\title{
Nexos y Diferencias Estudios de la Cultura de América Latina
}

$\mathrm{E}^{\mathrm{n}}$ nfrentada a los desafíos de la globalización y a los acelerados procesos de transformación de sus sociedades, pero con una creativa capacidad de asimilación, sincretismo y mestizaje de la que sus múltiples expresiones artísticas son su mejor prueba, los estudios culturales sobre América Latina necesitan de renovadas aproximaciones críticas. Una renovación capaz de superar las tradicionales dicotomías con que se representan los paradigmas del continente: civilizaciónbarbarie, campo-ciudad, centro-periferia y las más recientes que oponen nortesur y el discurso hegemónico al subordinado.

La realidad cultural latinoamericana más compleja, polimorfa, integrada por identidades múltiples en constante mutación e inevitablemente abiertas a los nuevos imaginarios planetarios y a los procesos interculturales que conllevan, invita a proponer nuevos espacios de mediación crítica. Espacios de mediación que, sin olvidar los nexos que histórica y culturalmente han unido las naciones entre sí, tengan en cuenta la diversidad que las diferencian y las que existen en el propio seno de sus sociedades multiculturales y de sus originales reductos identitarios, no siempre debidamente reconocidos y protegidos.

La Colección Nexos y Diferencias se propone, a través de la publicación de estudios sobre los aspectos más polémicos y apasionantes de este ineludible debate, contribuir a la apertura de nuevas fronteras críticas en el campo de los estudios culturales latinoamericanos.

\section{Consejo EDITORIAL}

Marco Thomas Bosshard (Europa-Universität Flensburg)

Luis Duno Gottberg (Rice University, Houston)

Oswaldo Estrada (The University of North Carolina at Chapel Hill)

Margo Glantz (Universidad Nacional Autónoma de México)

Beatriz González Stephan (Rice University, Houston)

Gustavo Guerrero (Université de Cergy-Pontoise)

Jorge J. Locane (Universitetet i Oslo)

Jesús Martín-Barbero (Bogotá)

Andrea Pagni (Friedrich-Alexander-Universität Erlangen-Nürnberg)

Mary Louise Pratt (New York University)

Patricia Saldarriaga (Middlebury College)

Friedhelm Schmidt-WeLle (Ibero-Amerikanisches Institut, Berlin) 


\title{
LA VIOLENCIA EN EL CONTINENTE AMERICANO DESDE EL RÍO BRAVO A LAS MALVINAS
}

¿Una semilla latente?

\author{
María Alonso Alonso \\ Gabriela Rivera Rodríguez (eds.)
}


Este libro forma parte de las actividades realizadas, dentro del proyecto "Narrativas de las nuevas diásporas", por el grupo de investigación EL\&CIN del Departamento de Literatura Española y Teoría de la Literatura de la Universidad de Vigo. Nuestro agradecimiento a la Universidad de Vigo y a la Xunta de Galicia por la financiación necesaria para llevar a cabo esta publicación.

Cualquier forma de reproducción, distribución, comunicación pública o transformación de esta obra solo puede ser realizada con la autorización de sus titulares, salvo excepción prevista por la ley. Diríjase a CEDRO (Centro Español de Derechos Reprográficos) si necesita fotocopiar o escanear algún fragmento de esta obra (www.conlicencia.com; $917021970 / 9327204$ 47).

(C) Iberoamericana, 2021

Amor de Dios, 1 - E-28014 Madrid

Tel.: +34914293522

(c) Vervuert, 2021

Elisabethenstr. 3-9 - D-60594 Frankfurt am Main

Tel.: +49695974617

info@ibero-americana.net

www.iberoamericana-vervuert.es

ISBN 978-84-9192-254-4 (Iberoamericana)

ISBN 978-3-96869-227-2 (Vervuert)

ISBN 978-3-96869-228-9 (e-Book)

Depósito legal: M-30108-2021

Diseño de cubierta: Rubén Salgueiros

Interiores: ERAI Producción Gráfica

The paper on which this book is printed meets the requirements of ISO 9706

La impresión de este libro se ha realizado sobre papel certificado FSC a partir de madera procedente de bosques gestionados de forma respetuosa con el medio ambiente, socialmente beneficiosa y económicamente sostenible.

Impreso en España 